\title{
Polypharmacy, medication adherence and medication management at home in elderly patients with multiple non-communicable diseases in Thai primary care
}

\author{
PASITPON VATCHARAVONGVAN ${ }^{1, A-G}$, VIWAT PUTTAWANCHAI ${ }^{1, A-G}$
}

Department of Community Medicine and Family Medicine, Faculty of Medicine, Thammasat University, Pathum-Thani, Thailand

A - Study Design, B - Data Collection, C - Statistical Analysis, D - Data Interpretation, E - Manuscript Preparation, F - Literature Search, G - Funds Collection

Summary Background. Polypharmacy among elderly patients in primary care settings is a global phenomenon that has not been well examined in Thailand.

Objectives. To determine (i) the prevalence rate of polypharmacy (using $\geq 5$ medications) among elderly Thai patients $\geq 60$ years of age who were diagnosed with multiple non-communicable diseases (NCDs) in primary care, (ii) medication adherence and (iii) quality of home medication management.

Material and methods. The electronic medical records of eligible patients were reviewed to obtain demographic data, current medications, medical diagnoses and medical outcomes such as blood pressure. Those with polypharmacy were interviewed at their homes using structured questionnaires to examine medication adherence and medication management at home. Data was collected between September 2014 and April 2015.

Results. Of the 397 participants, $146(36.8 \%)$ had polypharmacy. Those with polypharmacy were more likely to have type 2 diabetes mellitus, poor disease control and more NCDs. High rates of poor medication adherence $(61 \%)$ and poor medication management $(60.2 \%)$ at home were found in the polypharmacy group, but these factors were not associated with poor disease control ( $p=0.169$ and $p=0.683$, respectively).

Conclusions. More than one-third of the sample of Thai elderly with multiple NCDs in primary care were recipients of polypharmacy. Of those with polypharmacy, almost two-thirds reported poor medication adherence and poor medication management at home. Strategies to decrease unnecessary polypharmacy and improve both medication adherence and home management are essential in this patient group.

Key words: aged, chronic diseases, polypharmacy, primary care, patient adherence.

Vatcharavongvan P, Puttawanchai V. Polypharmacy, medication adherence and medication management at home in elderly patients with multiple non-communicable diseases in Thai primary care. Fam Med Prim Care Rev 2017; 19(4): 412-416, doi: https://doi. org/10.5114/fmpcr.2017.70818

\section{Background}

Polypharmacy, or the concurrent use of multiple medications, among the elderly is a global phenomenon. Recent data from Scotland indicates an increase in the prevalence of polypharmacy in this age group [1]. Approximately half of the elderly use multiple medications in various settings [2-4], including in primary care $[5,6]$. A study of Scottish primary care patients reported that $36 \%$ of elderly patients aged $60-69$ years used four or more medications concurrently and that this prevalence increased to $70.4 \%$ in those aged $\geq 80$ years [7]. The medications prescribed in ambulatory care settings covered five main disease areas: cardiovascular, endocrine, central nervous system, digestive and psychiatric diseases [7-9]. The factors associated with polypharmacy included increasing age, the number of comorbid diseases, the number of health care visits and specific diseases such as type 2 diabetes mellitus (T2DM) and hypertension $(\mathrm{HT})[10,11]$. In a study conducted in Finland, elderly diabetic patients had a two-fold greater risk of polypharmacy (2.28, 95\% confidence interval $[\mathrm{Cl}] 1.26-4.15)$ compared to those without diabetes [12].

Polypharmacy among the elderly has not been well examined in developing countries, including Thailand, but it may be common. Thailand has become an ageing society since 2007
[13], and the proportion of elderly increased from $10.7 \%$ (7 million) in 2007 to $14.9 \%$ (10 million) in 2014 . More than two million elderly Thai adults (18.3\%) have one or more non-communicable diseases (NCDs) [14], which means that they may need multiple medications to control their NCDs. Coupled with the universal coverage health plan launched in 2002 and the unrestricted access to over-the-counter medications, elderly Thai patients are at risk of taking multiple medications.

\section{Objectives}

A primary objective of this study is to examine the prevalence of polypharmacy among elderly patients aged 60 years or older with multiple NCDs in primary care. A secondary objective is to explore medication adherence and medication management at home in those with polypharmacy.

\section{Material and methods}

\section{Study design}

A cross-sectional survey study using electronic medical records (EMRs) and face-to-face interviews at the homes of partic- 
ipants with polypharmacy was conducted between September 2014 and December 2015 at a primary care practice in Pathum-Thani, Thailand. According to Thailand's Older Persons Act of 2003 , individuals are defined as elderly if they are $\geq 60$ years of age. This study was approved by the Human Ethics Committee of Thammasat University No. I, Faculty of Medicine, Thammasat University (MTU-EC-CF-2-072/57). A review of the electronic medical records (EMRs) was approved by the director of the primary care practice.

\section{Participants and data collection}

The EMRs of 394 patients aged $\geq 60$ years were selected using a systematic random sampling method. Inclusion criteria were elderly patients with $\geq 2$ following NCDs: T2DM, hyperlipidemia, $\mathrm{HT}$, ischemic heart disease, chronic heart failure, cerebrovascular disease and epilepsy. Age-eligible patients were excluded if they had not been prescribed medications for their NCDs for at least 6 months prior to recruitment.

Data collection included two steps. To determine the proportion of polypharmacy, the EMRs of eligible patients were reviewed. Those with polypharmacy ( $\geq 5$ medications for their NCDs) were invited to face-to-face interviews to examine medication adherence and medication management at home using structured questionnaires. Signed informed consent was obtained from all patients who participated in the interviews.

\section{Statistical analysis}

Poor medication adherence was defined as having at least one medication for NCDs that was (a) taken at the wrong time, (b) missed or (c) intentionally stopped by the patients. To reduce recall bias, patients were asked about incidents of poor medication adherence that occurred in the two weeks prior to the interview. Poor medication management at home was defined as the occurrence of at least one of the following: (a) removing medications from medication packages, (b) having expired or duplicated current medications at home, (c) having unused medications at home or (d) sharing medications with other people.

The patients were categorized into two groups: good and poor disease control. Patients with good disease control were those with any one of the following criteria: (a) fasting blood sugar was between $90-130 \mathrm{mg} / \mathrm{dL}$ in patients with T2DM during the last two visits, (b) systolic and diastolic blood pressure was lower than 150 and $90 \mathrm{~mm} \mathrm{Hg}$, respectively, in patients with HT during the last two visits, and (c) there were no hospital admissions due to NCDs within the previous six months.

Descriptive statistics were used to analyze the socio-demographic data, the prevalence of polypharmacy and the proportions of variables related to medication management at home and medication adherence. Chi-squared and Fisher's exact tests were used to compare proportions, and an independent Student's $t$-test was used to analyze the mean differences between the groups. A $p$-value $<0.05$ indicated statistical significance.

\section{Results}

\section{Participants}

The EMRs of 397 patients were included in the data analysis. Table 1 illustrates the characteristics of the patients. The mean age of the patients was 70 years (standard deviation, SD =6). Hypertension was the most common diagnosis (96.2\%). The median numbers of NCDs and medications used were 2 and 4 , respectively. Only half of the patients had good disease control.

\section{Polypharmacy}

Of the patients included in the sample, 146 (36.8\%) used five or more medications. Compared to the non-polypharmacy group, the polypharmacy group had more NCDs and was less likely to have good disease control and dyslipidemia, but was more likely to have T2DM (Table 1). There were no statistically significant differences in the mean age, gender, marital status or proportions of the remaining NCDs.

\begin{tabular}{|c|c|c|c|c|c|}
\hline \multirow{3}{*}{$\begin{array}{l}\text { Characteristics } \\
\text { Age - mean (SD) }\end{array}$} & \multicolumn{4}{|c|}{ Polypharmacy } & \multirow{3}{*}{\begin{tabular}{|l|}
$p$ \\
0.078 \\
\end{tabular}} \\
\hline & \multicolumn{2}{|c|}{ Yes $(n=146)$} & \multicolumn{2}{|c|}{ No $(n=251)$} & \\
\hline & 69 & (6) & 70 & (6) & \\
\hline Female $-n(\%)$ & 97 & $(66.4)$ & 186 & $(74.1)$ & 0.104 \\
\hline $\begin{array}{l}\text { Marital status } \\
\text { - married - } n(\%)\end{array}$ & 96 & $(65.8)$ & 171 & (68.1) & 0.627 \\
\hline $\begin{array}{l}\text { Number of chronic } \\
\text { diseases }- \text { median }^{\text {a }}\end{array}$ & 3 & & 2 & & $<0.001$ \\
\hline \multicolumn{6}{|l|}{ Diseases $^{\mathrm{b}}-n(\%)$} \\
\hline $\mathrm{HT}$ & 143 & (97.9) & 239 & (95.2) & 0.170 \\
\hline DLP & 97 & $(66.4)$ & 226 & $(90.0)$ & $<0.001$ \\
\hline T2DM & 126 & $(86.3)$ & 60 & (23.9) & $<0.001$ \\
\hline CAD & 4 & $(2.7)$ & 7 & $(2.8)$ & 1.000 \\
\hline CVD & 5 & (3.4) & 6 & $(2.4)$ & 0.542 \\
\hline $\mathrm{CHF}$ & 2 & $(1.4)$ & 2 & $(0.8)$ & 0.627 \\
\hline Epilepsy & 0 & $(0)$ & 1 & $(0.4)$ & 1.000 \\
\hline $\begin{array}{l}\text { Number of medications }{ }^{\mathrm{a}} \\
\text { - median (interquartile } \\
\text { range) }\end{array}$ & 6 & (2) & 3 & (2) & $<0.001$ \\
\hline $\begin{array}{l}\text { Good disease control }{ }^{d} \\
-n(\%)\end{array}$ & $36^{c}$ & $(24.8)$ & $169^{c}$ & (67.9) & $<0.001$ \\
\hline
\end{tabular}

${ }^{a}$ Mann-Whitney U test; ${ }^{\text {b }} \mathrm{HT}$ - hypertension; DLP - dyslipidemia; T2DM - type 2 diabetes mellitus; CAD - coronary artery disease; CVD - cerebrovascular disease; CHF - chronic heart failure; ${ }^{C}$ missing data $=1$; ${ }^{d}$ good disease control was defined as those with any one of the following criteria: (a) fasting blood sugar between $90-130 \mathrm{mg} / \mathrm{dL}$ in patients with T2DM during the last two visits, (b) systolic and diastolic blood pressure lower than 150 and $90 \mathrm{~mm} \mathrm{Hg}$, respectively, in patients with HT during the last two visits and (c) no hospital admissions due to NCDs within the previous six months.

\section{Medication management at home}

All patients with polypharmacy were invited for face-to-face interviews; 124 (84.9\%) agreed to participate. Of the interviewees, $61 \%$ reported poor medication adherence, such as taking medications at the wrong time, and $60.2 \%$ reported poor medication management at home, such as removing medications from medication packages. Approximately $80 \%$ managed their medication themselves, and the rest had their medication managed by a relative. Compared to those with good disease control, those with poor disease control had more chronic diseases and storage locations and were more likely to have T2DM and unused medications. Poor medication adherence and poor medication management at home were not associated with poor disease control (Table 2). 


\begin{tabular}{|c|c|c|c|c|c|}
\hline \multirow{3}{*}{$\begin{array}{l}\text { Characteristics } \\
\text { Age - mean (SD) }\end{array}$} & \multicolumn{4}{|c|}{ Disease control ${ }^{c}$} & \multirow{3}{*}{$\begin{array}{l}p \\
0.353\end{array}$} \\
\hline & \multicolumn{2}{|c|}{ Poor $(n=94)$} & \multicolumn{2}{|c|}{ Good $(n=30)$} & \\
\hline & 69 & $(5)$ & 70 & $(6)$ & \\
\hline Female $-n(\%)$ & 62 & (66) & 20 & $(66.7)$ & 0.943 \\
\hline $\begin{array}{l}\text { Number of chronic } \\
\text { diseases - mean (SD) }\end{array}$ & 3 & $(0.6)$ & 2 & $(0.5)$ & 0.006 \\
\hline \multicolumn{6}{|l|}{ Diseases $^{\mathrm{a}}-n(\%)$} \\
\hline $\mathrm{HT}$ & 92 & (97.9) & 29 & $(96.7)$ & 0.568 \\
\hline DLP & 59 & $(62.8)$ & 24 & $(80.0)$ & 0.081 \\
\hline T2DM & 89 & (94.7) & 17 & $(56.7)$ & $<0.001$ \\
\hline $\begin{array}{l}\text { Number of medica- } \\
\text { tions - mean (SD) }\end{array}$ & 6 & (1) & 6 & (1) & 0.099 \\
\hline $\begin{array}{l}\text { Number of medication } \\
\text { storage locations - } \\
\text { mean (SD) }\end{array}$ & 2.0 & $(0.6)$ & 1.7 & $(0.5)$ & 0.004 \\
\hline $\begin{array}{l}\text { Poor medication } \\
\text { adherence }-n(\%)\end{array}$ & $59^{b}$ & $(64.1)$ & 15 & $(50.0)$ & 0.169 \\
\hline $\begin{array}{l}\text { Taken at the } \\
\text { wrong time }\end{array}$ & 37 & (39.4) & 9 & $(30.0)$ & 0.355 \\
\hline Missed medications & 51 & $(54.3)$ & 12 & $(40.0)$ & 0.174 \\
\hline Stopped intentionally & $9^{c}$ & (9.9) & 4 & $(13.3)$ & 0.734 \\
\hline $\begin{array}{l}\text { Poor medication } \\
\text { management at home } \\
-n(\%)\end{array}$ & $56^{\mathrm{b}}$ & (60.9) & 17 & $(56.7)$ & 0.683 \\
\hline $\begin{array}{l}\text { Had expired medica- } \\
\text { tions }\end{array}$ & $12^{\mathrm{d}}$ & (12.9) & 1 & (3.3) & 0.184 \\
\hline $\begin{array}{l}\text { Had unused medica- } \\
\text { tions }\end{array}$ & 40 & $(42.6)$ & $6^{d}$ & $(20.7)$ & 0.033 \\
\hline $\begin{array}{l}\text { Removed medica- } \\
\text { tions from medica- } \\
\text { tion packages }\end{array}$ & $40^{d}$ & $(43.0)$ & 14 & $(46.7)$ & 0.726 \\
\hline $\begin{array}{l}\text { Had duplicate medi- } \\
\text { cations }\end{array}$ & $9^{d}$ & (9.7) & 2 & $(6.7)$ & 1.000 \\
\hline $\begin{array}{l}\text { Shared medications } \\
\text { with others }\end{array}$ & $14^{\mathrm{d}}$ & $(15.1)$ & 4 & (13.3) & 1.000 \\
\hline
\end{tabular}

${ }^{\mathrm{a}} \mathrm{HT}$ - hypertension; DLP - dyslipidemia; T2DM - type 2 diabetes mellitus; ${ }^{b}$ missing data $=2 ;{ }^{c}$ missing data $=3$; ${ }^{d}$ missing data $=1$; good disease control was defined as those with any one of the following criteria: (a) fasting blood sugar between $90-130 \mathrm{mg} / \mathrm{dL}$ in patients with T2DM during the last two visits, (b) systolic and diastolic blood pressure lower than 150 and $90 \mathrm{~mm} \mathrm{Hg}$, respectively, in patients with HT during the last two visits and (c) no hospital admissions due to NCDs within the previous six months.

\section{Discussion}

There is a paucity of research in polypharmacy among the elderly with multiple NCDs in developing countries [15]. Currently, there is still a need to understand polypharmacy in this particular group [16]. To respond to the need of evidence, this study explored polypharmacy, medication adherence and medication management in the homes of elderly patients with multiple NCDs in primary care in Thailand. The prevalence of polypharmacy in the elderly patients was almost $37 \%$. Most patients with polypharmacy managed medications at home themselves. Approximately two-thirds of the polypharmacy patients exhibited poor medication adherence or poor medication management at home.

The prevalence rate of polypharmacy in this study was similar to previous studies $[3-5,17,18]$ reporting polypharmacy rates between $25 \%$ and $50 \%$ in elderly patients. The elderly patients with polypharmacy were more likely to have T2DM, more NCDs and poor disease control than those without polypharmacy. The proportion of T2DM in the polypharmacy group was higher than the findings of Jyrkkä et al. [12], which may be explained by the high proportion of T2DM patients in our study. Regarding the number of NCDs, our study supports previous studies $[10,19]$ suggesting that elderly patients with several NCDs are more likely to have polypharmacy.

Standard practice guidelines for treating NCDs [e.g. 20] partly contribute to the use of polypharmacy to control NCDs and prevent their complications, especially in patients with poor disease control. However, an association between the quality of disease control and polypharmacy has not been well explored. In our study, $75.2 \%$ of those with poor disease control had polypharmacy, which may imply that they needed multiple medications due to poor disease control.

Polypharmacy is one of the risks of potentially inappropriate prescriptions and is related to negative health outcomes. Implementing an appropriate intervention can minimize unnecessary polypharmacy [21]. In primary care, a systematic approach of professional education with continuing support can improve appropriate prescriptions to the elderly [22-25]. A multi-professional intervention, such as LAKSAK, showed that potentially inappropriate mediations decreased by $22 \%$ after the intervention [22].

Elderly patients generally exhibit poor medication adherence, which is worse in those on multiple medications [10]. In our study, the rate of poor adherence was high (approximately $60 \%)$, similar to rates reported by others [10]. The findings call for active steps by medical doctors and pharmacists in primary care to monitor the medication adherence of these patients and provide a patient-centered education program to improve medication adherence [26].

In our study, more than half of the patients with polypharmacy reported poor medication management at home, such as having unused prescription medications. Compared to previous work in Australia [27], our rate of having expired medications was lower (10.6\% vs $19.6 \%)$, whereas the rate of unused medications was higher (37.4\% vs $21.1 \%)$. Nevertheless, the high proportion of poor medication management at home was not associated with poor disease control.

There were some limitations in this study. First, the prevalence of polypharmacy in this study may be under-estimated, as only the medications for six specific NCDs were examined. Over-the-counter medications and medications for other conditions that require multiple medications, such as mental illness and orthopedic conditions, were not included for analysis. Next, data was collected from patients at only one time point, and the prevalence of poor adherence could be better or worse at other time points. The operational definition of poor medication adherence was very strict and possibly resulted in an overestimation of poor medication adherence. However, Sakthong et al. [28] supported this approach, as it improves the sensitivity for detecting poor medication adherence. Finally, the sample size in the polypharmacy group was relatively small, which limited our statistical power; this may explain why some comparisons were not statistically significant, e.g. the lack of association between disease control and medication adherence.

\section{Conclusions}

More than one third of elderly Thai patients with multiple NCDs in primary care reported polypharmacy with a high proportion of poor medication adherence and poor medication management at home. These findings urge primary care practices to implement evidence-based interventions to prevent unnecessary polypharmacy and improve medication adherence and medication management at home in elderly patients with polypharmacy. Further research is required to examine other medical conditions that require multiple medications, as well as the factors affecting polypharmacy and medication-related problems associated with polypharmacy. 
Acknowledgements. The authors thank Dr. Wisree Warurakul, director of the primary care practice, for facilitating data collection from the electronic medical records. The authors also appreciate Professor Doctor Surasak Buranatrevedh for com- ments regarding the proposal and manuscript preparation, as well as Dr. Bob Taylor for comments on the manuscript. The authors thank all the patients who warmly welcomed us during the interviews at their homes.

Source of funding: This study was supported by the Thailand Research Fund (TRG5780025) in 2014, without a role of study design and publication.

Conflict of interest: The authors declare no conflict of interests.

\section{References}

1. Guthrie B, Makubate B, Hernandez-Santiago V, et al. The rising tide of polypharmacy and drug-drug interactions: population database analysis 1995-2010. BMC medicine 2015; 13(1): 74, doi: 10.1186/s12916-015-0322-7.

2. Herr M, Robine JM, Pinot J, et al. Polypharmacy and frailty: prevalence, relationship, and impact on mortality in a French sample of 2350 old people. Pharmacoepidemiol Drug Saf 2015; 24(6): 637-646.

3. Junius-Walker U, Theile G, Hummers-Pradier E. Prevalence and predictors of polypharmacy among older primary care patients in Germany. Fam Pract 2007; 24(1): 14-19.

4. Loya A, González-Stuart A, Rivera J. Prevalence of polypharmacy, polyherbacy, nutritional supplement use and potential product interactions among older adults living on the United States-Mexico border. Drugs Aging 2009; 26(5): 423-436.

5. Slabaugh SL, Maio V, Templin M, et al. Prevalence and risk of polypharmacy among the elderly in an outpatient setting: a retrospective cohort study in the Emilia-Romagna Region, Italy. Drugs Aging 2010; 27(12): 1019-1028.

6. Ahmed B, Nanji K, Mujeeb R, et al. Effects of polypharmacy on adverse drug reactions among geriatric outpatients at a tertiary care hospital in Karachi: a prospective cohort study. PLOS ONE 2014; 9(11): e112133, doi: 10.1371/journal.pone.0112133.

7. Payne RA, Avery AJ, Duerden M, et al. Prevalence of polypharmacy in a Scottish primary care population. Eur J Clin Pharmacol 2014; 70(5): 575-581.

8. Maher RL, Hanlon JT, Hajjar ER. Clinical consequences of polypharmacy in elderly. Expert Opin Drug Saf 2014; 13(1): 57-65.

9. Lenander $\mathrm{C}$, Midlov $\mathrm{P}$, Viberg $\mathrm{N}$, et al. Use of antipsychotic drugs by elderly primary care patients and the effects of medication reviews: a cross-sectional study in Sweden. Drugs Real World Outcomes 2017; 4(3): 159-165.

10. Hajjar ER, Cafiero AC, Hanlon JT. Polypharmacy in elderly patients. Am J Geriatr Pharmacother 2007; 5(4): 345-351, doi: 10.1016/j. amjopharm.2007.12.002.

11. Peron EP, Ogbonna KC, Donohoe KL. Antidiabetic medications and polypharmacy. Clin Geriatr Med 2015; 31(1): $17-27$.

12. Jyrkkä J, Enlund $\mathrm{H}$, Korhonen $\mathrm{M}$, et al. Patterns of drug use and factors associated with polypharmacy and excessive polypharmacy in elderly persons. Drugs Aging 2009; 26(6): 493-503.

13. National Statistical Office. The 2014 survey of the older persons in Thailand. Bangkok: Text and Journal Publication; 2014.

14. Aekplakorn W, Puckcharern H, Thaikla K, et al. Fifth national health examination survey 2014. Bangkok: National Health Research Institute; 2016.

15. Sirois C, Laroche M-L, Guénette, L et al. Polypharmacy in multimorbid older adults: protocol for a systematic review. Syst Rev 2017; 6: 104, doi: 10.1186/s13643-017-0492-9.

16. Leelakanok N, Holcombe AL, Lund BC, et al. Association between polypharmacy and death: a systematic review and meta-analysis. J Am Pharm Assoc 2017; pii: S1544-3191(17)30714-8, doi: 10.1016/j.japh.2017.06.002 [Epub ahead of print].

17. Haider $\mathrm{S}$, Johnell $\mathrm{K}$, Thorslund $\mathrm{M}$, et al. Trends in polypharmacy and potential drug-drug interactions across educational groups in elderly patients in Sweden for the period 1992-2002. Int J Clin Pharmacol Ther 2007; 45(12): 643-653.

18. Fialová $\mathrm{D}$, Topinková E, Gambassi G, et al. Potentially inappropriate medication use among elderly home care patients in Europe. JAMA 2005; 293(11): 1348-1358.

19. Jörgensen $T$, Johansson $S$, Kennerfalk A, et al. Prescription drug use, diagnoses, and healthcare utilization among the elderly. Ann Pharmacother 2001; 35(9): 1004-1009.

20. American Diabetes Association. Standards of medical care in diabetes - 2017: summary of revisions. Diabetes Care 2017; 40(Suppl. 1): S4-S5.

21. Patterson SM, Cadogan CA, Kerse N, et al. Interventions to improve the appropriate use of polypharmacy for older people. Cochrane Database Syst Rev 2012; 5: CD008165, doi: 10.1002/14651858.CD008165.pub2.

22. Lenander C, Bondesson A, Viberg N, et al. Effects of an intervention (SAKLAK) on prescription of potentially inappropriate medication in elderly patients. Fam Pract 2017; 34(2): 213-218.

23. Lenander $C$, Bondesson A, Midlov $P$, et al. Healthcare system intervention for safer use of medicines in elderly patients in primary carea qualitative study of the participants' perceptions of self-assessment, peer review, feedback and agreement for change. BMC Fam Pract 2015; 16: 117, doi: 10.1186/s12875-015-0334-6.

24. Tamblyn R, Huang A, Perreault R, et al. The medical office of the $21^{\text {st }}$ century (MOXXI): effectiveness of computerized decision-making support in reducing inappropriate prescribing in primary care. CMAJ 2003; 169(6): 549-556.

25. Taylor CT, Byrd DC, Krueger K. Improving primary care in rural Alabama with a pharmacy initiative. Am J Health Syst Pharm 2003; 60(11): 1123-1129.

26. Moral RR, Torres LA, Ortega LP, et al. Effectiveness of motivational interviewing to improve therapeutic adherence in patients over 65 years old with chronic diseases: a cluster randomized clinical trial in primary care. Patient Educ Couns 2015; 98(8): 977-983.

27. Sorensen L, Stokes JA, Purdie DM, et al. Medication management at home: medication-related risk factors associated with poor health outcomes. Age Ageing 2005; 34(6): 626-632.

28. Sakthong $\mathrm{P}$, Chabunthom R, Charoenvisuthiwongs R. Psychometric properties of the Thai version of the 8-item Morisky Medication Adherence Scale in patients with type 2 diabetes. Ann Pharmacother 2009; 43(5): 950-907.

Tables: 2

Figures: 0

References: 28 
Received: 31.08 .2017

Revised: 25.09 .2017

Accepted: 25.09.2017

Address for correspondence:

Pasitpon Vatcharavongvan, MD, PhD

Department of Community Medicine and Family Medicine

Faculty of Medicine

Thammasat University

Pathum-Thani 12120

Thailand

Tel.: +6629269802

E-mail: pasitpon@staff.tu.ac.th 